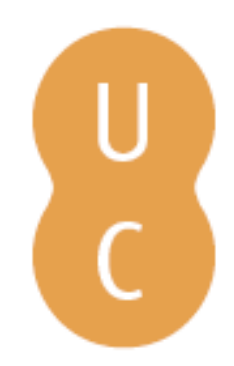

\title{
nombalina
}

\section{Riscos e perigos em tradução: considerações sobre terminologia nas ciências cindínicas}

\author{
Autor(es): $\quad$ Pedro, Isabel \\ Publicado por: Imprensa da Universidade de Coimbra \\ URL \\ persistente: URI:http://hdl.handle.net/10316.2/35750 \\ DOI: $\quad$ DOI:http://dx.doi.org/10.14195/978-972-8330-23-1_5 \\ Accessed : $\quad$ 26-Apr-2023 13:46:01
}

A navegação consulta e descarregamento dos títulos inseridos nas Bibliotecas Digitais UC Digitalis, UC Pombalina e UC Impactum, pressupõem a aceitação plena e sem reservas dos Termos e Condições de Uso destas Bibliotecas Digitais, disponíveis em https://digitalis.uc.pt/pt-pt/termos.

Conforme exposto nos referidos Termos e Condições de Uso, o descarregamento de títulos de acesso restrito requer uma licença válida de autorização devendo o utilizador aceder ao(s) documento(s) a partir de um endereço de IP da instituição detentora da supramencionada licença.

Ao utilizador é apenas permitido o descarregamento para uso pessoal, pelo que o emprego do(s) título(s) descarregado(s) para outro fim, designadamente comercial, carece de autorização do respetivo autor ou editor da obra.

Na medida em que todas as obras da UC Digitalis se encontram protegidas pelo Código do Direito de Autor e Direitos Conexos e demais legislação aplicável, toda a cópia, parcial ou total, deste documento, nos casos em que é legalmente admitida, deverá conter ou fazer-se acompanhar por este aviso.

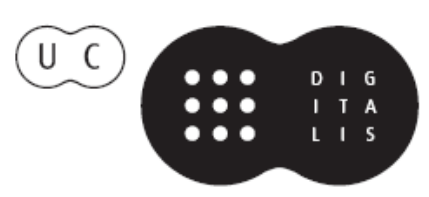




\section{REALIDADES E DESAFIOS NA GESTÃO DOS RISCOS}

\section{Diálogo entre Ciência e Utilizadores}

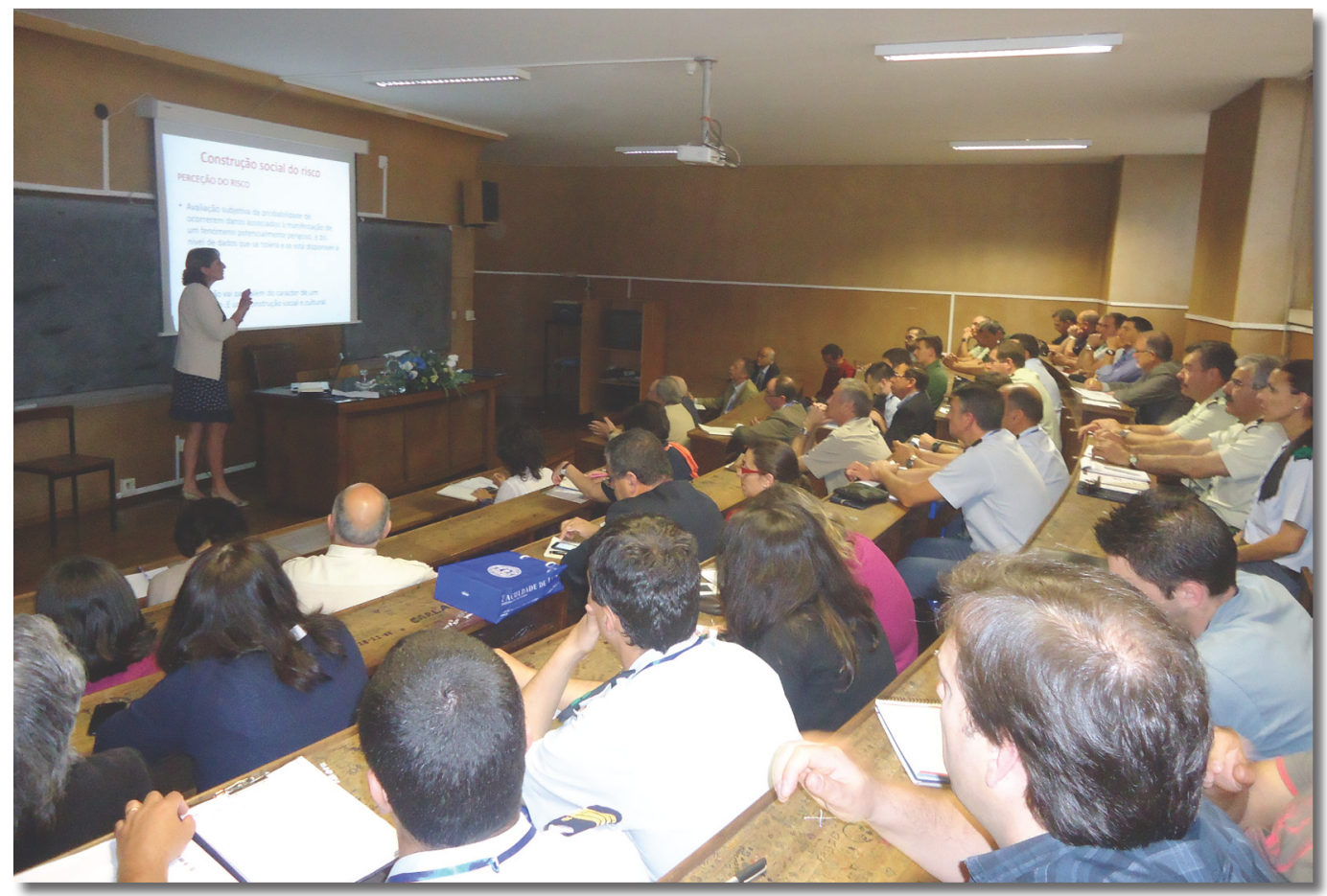

Núcleo de Investigação Científica de Incêndios Florestais

Faculdade de Letras da Universidade de Coimbra

Coimbra 


\title{
Capítulo V \\ RISCOS E PERIGOS EM TRADUÇÃO. \\ CONSIDERAÇÕES SOBRE TERMINOLOGIA NAS CIÊNCIAS CINDÍNICAS
}

\author{
Isabel Pedro \\ Faculdade de Letras da \\ Universidade de Coimbra \\ isabel_pedro@sapo.pt
}

\section{Introdução}

$\mathrm{Na}$ "Nota de Abertura" do $\mathrm{n}^{\circ} 16$ da Revista Territorium, em que é publicada uma série de artigos, da autoria de especialistas de diversas áreas científicas e em diferentes línguas, sobre a temática dos riscos, Fernando Rebelo afirma reconhecer que "numa área científica multidisciplinar, como a dos riscos, as divergências de linguagem são perfeitamente aceitáveis". Refere depois, apesar disso, que identifica a existência de "dificuldades em traduzir certas palavras inglesas ou francesas", as quais, diz: "têm levado a muitas confusões". Dados alguns exemplos do problema, que ilustra sobretudo com o termo inglês hazard, e sugerindo algumas hipóteses de solução, o autor convida então os leitores da revista a fazerem "um esforço de entendimento de idiomas e de conceitos". ${ }^{1}$

O contexto em causa é o das Ciências Cindínicas, uma área de conhecimento recente, de natureza multidisciplinar, o que por si só parece poder justificar a ausência de uma terminologia consensual e normalizada. Nos cada vez mais intensos intercâmbios internacionais (e também nos nacionais), nos diversos fora e nas inúmeras publicações da área, a dilucidação de conceitos e de modelos teóricos e o estabelecimento de equivalências terminológicas têm claramente vindo a ser sentidos como uma necessidade. ${ }^{2}$

Nesse âmbito, do ponto de vista de uma estudiosa de línguas e de tradução (e também tradutora), as observações do autor que comecei por citar parecem-me extremamente pertinentes, porquanto, ao invés de pressuporem uma relação unívoca e isenta de tensões entre termos do mesmo sistema linguístico ou, a um outro nível, entre termos ditos "equivalentes" em duas línguas diferentes, deixam perceber um entendimento mais complexo da linguagem e do seu funcionamento e, portanto, uma consciência perspicaz da problemática da tradução (e dos seus riscos).

É, de facto, necessário, fazer-se "um esforço de entendimento de idiomas e de conceitos". Se a língua que usamos parece apresentar-se-nos como "natural", já o confronto de línguas não pode deixar de evidenciar a não linearidade da sua relação com o mundo como o concebemos, percecionamos e sentimos (nas várias línguas, na nossa própria língua).

A linguagem, e refiro sobretudo, claro, a linguagem verbal, é o meio humano privilegiado de descrever o "real" e de o comunicar. É, obviamente também, o meio de "dominarmos" esse real, aliás um dos objetivos de sempre da ciência e dos seus discursos. Porém, é necessária a consciência de que, parafraseando Jonathan Culler, os objetos e os acontecimentos não são simplesmente objetos e acontecimentos em si mesmos e sim objetos e acontecimentos sempre já com significado, ou melhor, com significados, culturalmente atribuídos ou impostos.

\footnotetext{
${ }^{1}$ Cf ainda, do mesmo autor, em número posterior da revista: «Toda esta diversidade vem enriquecendo a Territorium. Por um lado, a variedade temática, por outro lado a dispersão espacial. Mas a formação dos autores leva-os, frequentemente, a utilizar designações diferentes para situações semelhantes. Como já tenho salientado em notas de abertura de números anteriores, isto não cria qualquer problema científico, mas exige grande atenção da parte dos leitores. A dificuldade em traduzir "hazard", por exemplo, continua a dar resultados curiosos quando aparecem palavras de que nunca nos tínhamos lembrado.". (Territorium 19, p. 3).

2 Ver, por exemplo, os «Comentários ao modelo proposto no Guia Técnico para Elaboração do PMDFCl», sob o título «"PERIGOS” DAS “CARTAS DE RISCO”», da autoria de Luciano LouRENço (Territorium 15, pp. 122-126). $O$ autor reconhece que alguns dos conceitos em causa não merecem ainda a concordância da generalidade da comunidade científica e refere inclusivamente a colisão de interpretações de modelos e respetivos conceitos existente entre diferentes organismos do Estado.
} 


\section{Realidades e desafios na gestão dos riscos \\ - Diálogo entre ciência e utilizadores -}

É necessário ainda perceber que tais acontecimentos e objetos, fenómenos e "coisas" não possuem "essências" mas se definem numa rede de relações internas e externas.

Como eles, os signos linguísticos que pretendem referi-los/descrevê-los/comunicá-los/ estabelecer relações entre eles e entre eles e nós não são "naturais" e não têm um significado intrínseco, antes obtêm o seu sentido, em cada contexto específico, no âmbito de uma rede de relações na qual ocupam determinado lugar, um lugar que é caracterizado/ identificado pela sua diferença em relação aos outros signos e thes concede um determinado valor, um - ou mais - sentido(s).

Importante para a presente discussão é a dimensão paradigmática dessa diferença, sendo que o valor/o sentido de um elemento depende das diferenças entre esse elemento e outros elementos que, numa dada sequência discursiva, ou sintagma, poderiam ter ocupado ou ocupar o mesmo lugar (e avancemos já, como exemplo, com os termos ingleses danger, hazard, peril, jeopardy, risk, ou mesmo threat, etc., os quais podem, de uma forma geral, ser considerados sinónimos, mas que, apesar disso - ou por essa mesma razão - não significam exatamente o mesmo. Voltaremos a esta questão mais adiante.

No caso dos signos linguísticos, como há muito ensinou SaUssure, o sentido tem uma base convencional e arbitrária; ou seja, a dinâmica de significação não funciona por semelhança, como um retrato que, por via da sua iconicidade, representa e significa a pessoa retratada, mas sim pela imposição de uma regra, uma lei que liga um significante a um significado (digamos que a forma da palavra, a parte material do signo, ao seu sentido, o conceito que evoca) sem uma prévia relação de semelhança, como a do ícone, ou de contiguidade, como a do índice (o fumo que indica fogo). ${ }^{3}$ Essa regra ou lei que estabelece a relação de significação é então a convenção, indissociável da arbitrariedade.

Isto significa que os laços que possibilitam e ancoram a significação são instáveis - enquanto a convenção é uma força que une significante e significado, gerada pela repetição (a regra no sentido de regularidade, mas também de normatização, dependente esta de uma autoridade reguladora do sentido), a imotivação do signo e a sua arbitrariedade implicam, no sentido oposto, a instabilidade, o carácter não definitivo dessa ligação. Digamos que, por um lado, a convenção permite que a língua possa funcionar como "comunicação", se quisermos, mas a arbitrariedade implica um espaço (o espaço do sujeito?) que impede que o sistema se feche e the confere dinamismo, gerando mudança e a possibilidade de atualização (e, por vezes, voltando a citar ReBelo, "muitas confusões").

Gostaria de observar brevemente que esse carácter arbitrário é aquele que induz a polissemia, os diferentes valores semânticos de uma mesma palavra, que permite o lado criativo da linguagem, que permite a expressão (mais do que a comunicação), que permite a metáfora e a poesia, e que, tradicionalmente, a ciência deveria minimizar na sua necessidade de controlo e (de)limitação do sentido, na sua histórica orientação para a comunicabilidade neutra e objetiva - que a linguagem de facto não permite.

A linguagem não existe sem o sujeito (e vice-versa, como defende BENVENISTE, o sujeito não existe sem a linguagem) e a relação da linguagem com aquilo a que chamamos "o real" é mediada exatamente por essa posição subjetiva, sempre presente. Sendo uma forma de descrever o real e de o conhecer, a linguagem (e qualquer língua) inclui necessariamente uma perspetiva, uma posição dentro desse real e sobre ele. Como facto cultural/ideológico que permite o nosso conhecimento daquilo a que chamamos, por exemplo, a natureza, a linguagem impede de facto que esse conhecimento seja objetivo, neutro, absoluto. Ou seja: a realidade-dita já não é a realidade e sim uma visão dela, tingida das cores da nossa visão do mundo, da organização do real que a nossa língua, a nossa história, a nossa cultura, a nossa "ciência" nos facultam, simultaneamente possibilitando, refletindo e limitando, ou pelo menos condicionando, o nosso contacto com esse real.

\footnotetext{
${ }^{3}$ A clássica tipologia do signo como ícone, índice ou símbolo, três formas diferentes de representação do objeto, deve-se a Charles Pierce.
} 
Assim, resumindo, vários ângulos convergentes nos podem ajudar a perceber esse fenómeno:

1. O sujeito como posição inevitável em qualquer ato de linguagem - porque é a única instância capaz de produzir o discurso, que o implica como situado no centro do sistema da língua e, por assim dizer, no centro do mundo;

2. A perspetiva desse sujeito;

3. A natureza convencional e arbitrária da unidade de sentido: o signo linguístico, cuja dinâmica é gerida, em qualquer ato de linguagem, em qualquer nomeação do real, pelo sujeito.

Há exemplos "clássicos" que nos permitem constatar como a linguagem produz e afeta a nossa experiência e o nosso conhecimento do mundo e como depende também desse mundo e dessa experiência. As diferentes línguas integram diferentes visões do mundo e diferentes formas de organização e conceptualização do real, funcionando cada uma na base de quadros de perceção específicos. 0 já lugar-comum do extensíssimo léxico Esquimó-Inuit relativo a neve, referido no séc. XIX pelo antropólogo Franz BoAs (e até hoje origem de grandes polémicas e de continuada discussão entre especialistas) é de alguma forma corroborado por estudos mais recentes, que revelam, por exemplo, que as línguas Esquimós (Yupic e Inuit) possuem dezenas, se não centenas, de palavras para neve e gelo; os Sami, no norte da Rússia e da Escandinávia, que também possuem pelo menos 180 vocábulos diferentes para neve e gelo, parecem ter um vocabulário de perto de 1000 termos diferentes para "rena", ou seja, existirá para os falantes dessas línguas um milhar de animais diferenciados por determinadas características relevantes, que são para nós - porque falamos Português e só possuímos o termo "rena" - impossíveis de conceptualizar/imaginar ou de distinguir como objetos diferentes! ${ }^{4}$

Mas não é necessário deslocarmo-nos tão longe em termos geográficos para percebermos, por exemplo, pelo contraste entre a língua portuguesa e a língua inglesa, uma diferente estruturação/conceptualização do mundo a partir daquele que é um conceito básico para a geografia: o espaço, e a sua divisão operada pela posicionalidade do sujeito na sua relação de oposição com o outro. Vejamos:

Inglês:

2 pólos

here / there
Português:

3 pólos

\section{Advérbios}

\begin{tabular}{|c|c|c|}
\hline \multirow{2}{*}{ here / there } & & aqui (cá) / aí / ali (lá ou acolá) \\
\hline & Demonstrativos & \\
\hline is (these) / that (those) & & $\begin{array}{l}\text { isto/ isso / aquilo (formas invariáveis } \\
\text { neutras) }\end{array}$ \\
\hline IIs (these) / Chat (triose) & & $\begin{array}{l}\text { este }(\mathrm{a})(\mathrm{s}) \text { / esse }(\mathrm{a})(\mathrm{s}) \text { / aquele }(\mathrm{a})(\mathrm{s}) \\
(\text { formas variáveis também em género) }\end{array}$ \\
\hline
\end{tabular}

A estes signos, que, com outros do mesmo tipo, marcam a posição do sujeito (da pessoa que fala e, dialogicamente, da sua interlocutora), no espaço ou no tempo, sinalizando, na sua auto-referencialidade, as condições específicas de cada enunciação ou ato de fala, chamamos deíticos, sendo os que apresentei conhecidos como topemas, uma vez que designam relações espaciais.

Como podemos ver, a divisão espacial disponível aos falantes de inglês, e, portanto, a sua conceptualização de espaço, é marcada por uma estrutura bipartida, distinguindo apenas o "próximo" (perto do sujeito) e o "distante" (longe do sujeito), enquanto em português

Cf.http://www.washingtonpost.com/national/health-science/there-really-are-50-eskimo-words-forsnow/2013/01/14/e0e3f4e0-59a0-11e2-beee-6e38f5215402_story.html (acedido a 15.5.2014) 


\section{Realidades e desafios na gestão dos riscos \\ - Diálogo entre ciência e utilizadores -}

existem outras distinções mais detalhadas, num paradigma espacial tripartido que tem por base a tríade das pessoas gramaticais: eu / tu / ele-ela. Assim, poderíamos dizer que em inglês o espaço do real é dividido em espaço-perto-de-mim e espaço-longe-de-mim enquanto em português existem "mais" ou "outros" espaços: o espaço-perto-de-mim, o espaço-não-tãoperto-de-mim-mas-perto-de-ti e o espaço-longe-de-mim-e-de-ti, que é o espaço do ele-ela.

Será então que há espaços em português que não existem em inglês? Poderíamos metaforicamente falar de espaços do real que, sendo "ausentes" numa determinada língua, são, por isso, intraduzíveis?

Nesse âmbito se situa, por exemplo, a questão da diferença/oposição entre hazard e risk (ou danger) em inglês, a qual não existe na língua portuguesa. Aqui estamos numa situação inversa: em inglês a noção de "perigo" é mais detalhada do que em português, há mais signos em oposição nessa área semântica na língua inglesa do que na portuguesa; ou seja, parece haver no inglês uma conceptualização mais complexa, mais elaborada, de perigo ou risco do que a que existe na nossa língua, o que, como é de esperar, causa necessariamente dificuldades conceptuais e problemas de tradução.

\section{A Questão da Sinonímia}

Podemos considerar que as palavras inglesas hazard e risk são sinónimas. Diferentes dicionários e thesauri postulam a relação de sinonímia entre esses termos e ainda outros como danger, peril, jeopardy, distress, threat, etc. ${ }^{5}$

Lembremos o que já foi referido sobre a dinâmica de significação: o sentido de um signo linguístico é um valor que depende de uma rede de relações (de contiguidade e de oposição/ potencial substituição num determinado contexto) - isto é, esse valor é uma função, por um lado, da diferença entre esse signo e os que o acompanham no discurso enunciado e, por outro, da diferença entre o mesmo signo e os signos disponíveis que poderiam ocupar o seu lugar. Neste caso estão, por exemplo, os sinónimos.

Ora os nossos sinónimos hazard e risk, ou ainda danger, peril, etc. podem, em determinados contextos, ter valores mais ou menos equivalentes ou relativamente sobreponíveis, mas, por definição, nunca serão absolutamente comutáveis. A questão é que não existem casos de sinonímia perfeita, estando sempre presentes, mesmo numa única língua, diferenças de valor semântico, variações conotativas, registos diversos, sempre dependentes do contexto em que os termos são usados.

Parece, aliás, haver até uma certa "hierarquização" destes vários termos na língua inglesa, segundo a qual, no seu uso comum, danger (perigo) funcionaria basicamente como hiperónimo dos outros, isto é, o termo mais geral cujo significado inclui os significados dos outros, seus hipónimos, cada um com conotações e implicações específicas, para além da área comum que os torna sinónimos. Hazard, ao mesmo tempo que pode ser sinónimo de danger ou de risk, é ainda um termo polissémico que também pode significar, entre outras coisas mais, chance, uncertainty, fortune ou ainda gambling e bunker, por exemplo ativando a ideia do aleatório, da incerteza, do jogo, ou ainda significando, num contexto muito específico, os obstáculos de água ou de areia num campo de golfe.

Assim, torna-se muito complexa a solução dos problemas de tradução de termos como estes, solução que terá sempre de passar pela consideração do contexto em causa, muito especialmente no âmbito daquilo a que os tradutores chamam a Língua de Chegada, a língua para a qual se traduz. Vejam-se algumas questões relativas exatamente à tradução de hazard, termo que, como já foi observado, não tem um equivalente conceptual nem verbal em português, obrigando em muitos contextos à sua substituição por um hiperónimo, como

\footnotetext{
${ }^{5}$ Como curiosidade, lembremos que existem ainda sinónimos menos próximos ou metáforas, como, por exemplo, crisis, dynamite, emergency, endangerment, exposure, havoc, hot potato, imperilment, insecurity, instability, menace, minefield, pitfall, storm, thin ice, trouble, uncertainty, venture, vulnerability...
} 


\section{Considerações sobre terminologia nas ciências cindínicas}

"perigo" ou "risco", termos e conceitos estes que levam necessariamente à perda de parte do significado específico da palavra inglesa em causa.

É óbvio que a tradução por um dos hiperónimos referidos, ou ainda, eventualmente, por outros termos, depende do contexto em causa e de todo um quadro conceptual específico, que ditará a opção tradutiva desta palavra sem equivalente imediato em português e lhe dará sentido. Há contextos em que, por exemplo, uma expressão como "hazardous materials" se traduz como "materiais perigosos" ou até se pode encontrar na base terminológica da UE, IATE, a expressão “contamination hazards" traduzida tanto por "risco de contaminação" como por "perigo de contaminação", com atribuição do mesmo grau de fiabilidade ${ }^{6}$.

Por outro lado, autores como Fernando ReBeLo e Luciano Lourenço, entre outros, têm defendido, no âmbito da Teoria do Risco e das Ciências Cindínicas e em contextos específicos como, por exemplo, o dos "incêndios florestais", que hazard deve ser traduzido por "risco" - e fazemno a partir de um quadro conceptual que situa o risco (em português) numa sequência de risco-perigo-crise, justificando assim teoricamente a opção de tradução do termo inglês em causa por "risco" e não por "perigo", já que aquele precede este, o que parece coadunar-se com o conceito original da palavra inglesa. Torna-se assim explícita a lógica conceptual que, num contexto muito preciso, preside a esta opção tradutória e a clarifica, legitimando-a e assegurando de algum modo o controlo do sentido.

É claro que, embora funcione satisfatoriamente no contexto em causa, não se pode dizer que se trata de uma tradução definitiva e absoluta, a única tradução "correta" ou possível. Evidentemente, ao traduzir-se hazard por "risco", termo que traduz diretamente o inglês risk, se perde a especificidade da diferença entre os dois conceitos ingleses discretos de hazard e risk (diferença ativa, por exemplo, no título de uma obra recentemente reeditada por GLADE e.a., Landslide Hazard \& Risk).

Notemos um exemplo simples da diferença entre os dois conceitos na linguagem comum: a existência de gelo ou neve numa estrada é um "hazard", mas o "hazard" não implica por si só que haja "risk" - se essa estrada for cortada ao trânsito, o risco desaparece, embora se mantenha o "hazard". Para que exista risco tem de haver uma exposição a esse "hazard"; portanto, a existência de "hazard" não implica em si a existência de risco se não houver exposição a ele. De facto, uma estrada com gelo ou neve cortada ao trânsito é um "hazard" mas não um risco - o nosso problema é que não existe essa distinção em português.

Assim, ao traduzir-se, agora na direção inversa, para inglês, o termo português "risco", por exemplo na aceção na qual ele é definido por REBELO e outros autores, poderá ser necessário fazê-lo usando em simultâneo os dois conceitos ingleses - "hazard and risk". Foi esta a solução encontrada no "Abstract" do artigo "Um novo olhar sobre os riscos? 0 exemplo das cheias rápidas (flash floods) em domínio mediterrâneo" (Territorium 15), de Fernando Rebelo, em que uma das palavras-chave do Resumo, "risco", surge traduzida no Abstract como "hazard and risk". Aliás, claramente consciente da inevitável imperfeição da tradução de hazard por "risco", o autor tem o cuidado de, na obra Geografia Física e Riscos Naturais, definir "hazard" como "o risco em sentido restrito" (p. 33), já que o articula, com DAUPHINÉ e outros autores, como uma das duas principais componentes do risco (sendo a outra a "vulnerabilidade").

Assistimos assim a um esforço de definição e demarcação do sentido a dar a determinados termos para que eles adquiram uma função específica no discurso especializado e se tornem, num determinado contexto e numa situação comunicativa específica, para além de signos da linguagem comum, unidades terminológicas, ou seja, para que facilitem a comunicação entre a comunidade de especialistas e a comunicação desta com os interessados, os utilizadores e o público em geral.

\footnotetext{
${ }^{6}$ http: / / iate.europa.eu/SearchByQuery.do?method=searchDetail\&lilld=1445118\&langld=\&query=hazard\&sourc eLanguage=en\&domain=0\&matching=\&start=50\&next=1\&targetLanguages=pt (acedido a 15.5.2014)

${ }^{7}$ No respetivo resumo francês, "risco" surge traduzido por "aléa et risque".
} 


\section{Realidades e desafios na gestão dos riscos \\ - Diálogo entre ciência e utilizadores -}

Como nota final, foi muito interessante verificar como os teóricos, os cientistas e os autores ligados às Ciências Cindínicas estão conscientes dos problemas colocados pelo uso da linguagem e pela complexidade da tradução, preocupando-se com, ou sentindo mesmo a necessidade de constante reflexão, clarificação/especificação de contextos, e definição e justificação de opções tradutivas e terminológicas. Longe de encararem comodamente a língua como um "instrumento de comunicação" objetivo e unívoco, ao serviço de uma visão positivista do mundo e da ciência, parecem exercer um permanente "esforço de entendimento de idiomas e de conceitos", mostrando-se disponíveis para lidar com as dinâmicas da linguagem e da tradução e, portanto, com os respetivos riscos.

\section{Bibliografia e Referências}

Benveniste, Émile (1974) - Problèmes de linguistique générale, 1. Paris: Gallimard, 1966; Problèmes de linguistique générale, 2 . Paris: Gallimard.

Culler, Jonathan (1975) - Structuralist Poetics: Structuralism, Linguistics and the Study of Literature. Ithaca: Cornell UP.

Glade, Thomas, e. a. (2005) - Landslide Hazard \& Risk. Chichester: John Wiley \& Sons Ltd.

LOURENço, Luciano (2008) - “«Perigos» das «Cartas de Risco». Comentários ao modelo proposto no Guia Técnico para Elaboração do PMDFCl”. Territorium, 15, p. 122-126. Disponível em: http:// www.uc.pt/fluc/nicif/riscos/Documentacao/Territorium/T15_artg/T15NNR11.pdf.

Rebelo, Fernando (2008) - "Um novo olhar sobre os riscos? O exemplo das cheias rápidas (flash floods) em domínio mediterrâneo". Territorium 15, p. 7-14. Disponível em: http:// www.uc.pt/fluc/nicif/riscos/Documentacao/Territorium/T15_artg/T15art02.pdf.

Rebeto, Fernando (2009) - “Nota de Abertura”. Territorium 16, p.3-4. Disponível em: http:/ / www. uc.pt/fluc/nicif/riscos/Documentacao/Territorium/T16_artg/T16Nota_de_abertura.pdf.

Rebelo, Fernando (2010) - Geografia Física e Riscos Naturais. Coimbra: IUC, 2010.

Rebelo,Fernando (2012) - "Nota de Abertura". Territorium 19 (2012), p. 3. Disponível em: http:// www.uc.pt/fluc/nicif/riscos/Documentacao/Territorium/T19_artg/Nota_de_Abertura.pdf.

Saussure, Férdinand de (1916) - Curso de Linguística Geral. Trad. José Victor Adragão. Lisboa: Publicações D. Quixote, 1986.



